DOI 10.37882/2223-2982.2021.12-2.26

\title{
ПРИМЕНЕНИЕ ИНТЕРАКТИВНОГО ПОСОБИЯ «ИГРОКУБ» В КОРРЕКЦИОННОЙ РАБОТЕ ПО РАЗВИТИЮ ОСЯЗАНИЯ И МЕЛКОЙ МОТОРИКИ У ДОШКОЛЬНИКОВ С ОБЩИМ НЕДОРАЗВИТИЕМ РЕЧИ
}

\section{APPLICATION OF THE INTERACTIVE TOOL "IGROKUB" IN CORRECTIVE WORK ON THE DEVELOPMENT OF TOUCH AND FINE MOTOR IN PRESCHOOLERS WITH GENERAL SPEECH IMPAIRMENT}

N. Minaeva

A. Zinyukhina

Summary: The article is devoted to the problem of improving correctional work on the development of touch and fine motor skills in children with general speech underdevelopment (GD) of preschool age. The authors considered the possibilities of using a specially developed interactive didactic manual "Igrokub" in the process of correctional classes aimed at developing the tactile and motor capabilities of preschoolers in this category. The article presents the results of an experimental study aimed at studying the features of the development of touch and fine motor skills of preschoolers with $\mathrm{OHP}$, and the development of the content and organizational and methodological aspects of corrective work on their development using the "Igrokub".

Keywords: touch, fine motor skills, preschoolers with general speech underdevelopment, correctional work, speech therapy classes, the «lgrokub» manual.
Минаева Наталья Геннадьевна

К.n.н., дочент, ФГБОУ ВО «Мордовский государственный педагогический университет имени М.Е. Евсевьева»

(2. Саранск)

natmi27@yandex.ru

Зинюхина Анастасия Владимировна

ФГБОУ ВО «Мордовский государственный педагогический университет имени М.Е. Евсевьева» (2. Саранск) znastya98@mail.ru

Аннотация: Статья посвящена проблеме совершенствования коррекционной работы по развитию осязания и мелкой моторики у детей с общим недоразвитием речи (ОНР) дошкольного возраста. Авторами рассмотрены возможности применения специально разработанного интерактивного дидактического пособия «Игрокуб» в процессе коррекционных занятий, направленных на развитие осязательных и моторных возможностей дошкольников данной категории. В статье представлены результаты опытно-экспериментального исследования, направленного на изучение особенностей развития осязания и мелкой моторики дошкольников с ОНР, и разработку содержания и организационно-методических аспектов проведения коррекционной работы по их развитию с применением «Игрокуба».

Ключевые слова: осязание, мелкая моторика, дошкольники с общим недоразвитием речи, коррекционная работа, логопедические занятия, пособие «Игрокуб».
И справление нарушений мелкой моторики и расширение осязательных возможностей ребенка с ограниченными возможностями здоровья, в том числе с нарушением речи, являются важными условиями подготовки его к жизни и, в последующем, к физическому труду, что показывает актуальность проблемы разработки новых технологий для развития моторных и тактильных способностей детей.

Также доказано, что активизация развития мелкой моторики рук является стимулирующим базисом для становления речи, психических процессов, познавательной деятельности дошкольников [4]. М.В. Земля- ченко, обобщая материалы исследований Т.Н. Андриевской, Л.В. Антаковой-Фоминой, Г.В. Беззубцевой, М.М. Кольцовой, Т.А. Ткаченко, отмечает, что систематическая работа по развитию мелкой моторики повышает эффективность коррекции речевых нарушений. На основании результатов проведённого исследования была обозначена взаимосвязь: при замедлении развития мелкой моторики задерживается и речевое развитие, при этом развитие общей моторики может быть в пределах возрастной нормы [2].

Осязанием как средством самокомпенсации пользуются дети с глубокими нарушениями зрения, глухие,

Исследование выполнено в рамках гранта на проведение научно-исследовательских работ по приоритетным направлениям научной деятельности вузов-партнеров по сетевому взаимодействию ФГБОУ ВО «Чувашский государственный педагогический университет им. И. Я. Яковлева» по теме «Научно-методические аспекты применения инновационных образовательных технологий в коррекционной работе с дошкольниками с ограниченными возможностями здоровья» 
дети с нарушениями речи и дети с нарушениями интеллекта. Однако, несмотря на значительную роль осязания для указанных категорий детей, часто оно не достигает достаточного уровня развития. Так, Р.Б. Каффеманас провел экспериментальное исследование осязательного восприятия аномальных детей (слабовидящих, глухих, детей с нарушениями речи, детей-олигофренов). Наблюдая в ходе эксперимента за осязательными движениями испытуемых, он отметил их асинхронность, большую хаотичность, недостаточную целенаправленность и точность, отсутствие организованности, пассивность осязательных движений [5, с. 14].

Особое внимание ученых привлекает проблема моторного развития дошкольников с нарушениями речи в контексте формирования физической готовности ребенка к школе. Л.И. Моурлот и Л.А. Ремезова отмечают, что для правильного удержания ребенком ручки и карандаша, для отсутствия усталости руки при письме, мышцы должны быть достаточно крепкими, что обеспечивается хорошо развитой мелкой моторикой [7].

Анализ исследований по проблеме развития осязания у старших дошкольников с общим недоразвитием речи показал, что данный вопрос рассмотрен недостаточно и остается открытым для дальнейшего рассмотрения. Однако С.С. Бобык при исследовании тактильной чувствительности (осязания) у детей с речевыми нарушениями отмечает наличие тактильной агнозии, заключающейся в сложности узнавания формы объектов при относительной сохранности поверхностной и глубокой чувствительности [1, с. 11].

Знание особенностей развития осязательной и сенсомоторной деятельности старших дошкольников с нарушениями речи позволяет выстраивать систему коррекционной работы по формированию у них данных навыков. Часто используемым методом развития мелкой моторики дошкольников является массаж кистей рук, а также упражнения с использованием тренажеров и эспандеров. Развитию изолированных движений рук, кистей и пальцев рук способствуют специальные упражнения, которые, по мнению Л.И. Моурлот и Л.А. Ремезовой, включают оптико-кинестетическую организацию движений, зрительно-пространственную организацию движений, динамическую организацию двигательного акта [7, с. 77]. Т.Б. Филичева и Г.В. Чиркина отмечают, что развитие ручной и пальцевой моторики эффективно осуществляется в процессе предметно-практической деятельности (конструирование, лепка, аппликация, рисование) [8].

Все большую роль для активизации развития осязания и мелкой моторики приобретают интерактивные дидактические пособия, способные не только обеспечить разнообразную деятельность, направленную на ак- тивизацию движений рук различной модальности, но и вызывать заинтересованность и желание ребенка заниматься благодаря вариативности игровых заданий с их использованием. В числе подобных пособий можно назвать бизиборды, лепбуки; в частности, одним из наиболее известных пособий для психологического развития и коррекции нарушений у детей с ОВ3 является игровой комплект «Пертра», разработанный известным педагогом М. Фростиг [3, с. 2].

С целью изучения уровня развития осязательных возможностей и мелкой моторики дошкольников с ОНР нами был проведен констатирующий эксперимент, в котором принимали участие 24 ребенка с логопедическим заключением «Общее недоразвитие речи III уровня» в возрасте 6-7 лет [6]. Его результаты позволили выделить три группы испытуемых по уровню развития осязания и мелкой моторики. К первой группе мы отнесли испытуемых с высоким уровнем, мелкая моторика и осязательные возможности таких детей развиты в пределах возрастной нормы. Данную группу составили 20,8 \% (5 человек) испытуемых. Вторую группу - со средним уровнем развития осязания и мелкой моторики - составили 54,2 \% (13 человек) испытуемых. У таких детей были отмечены затруднения в переносе жеста с одной руки на другую, незначительное нарушение согласованности и скованность движений, слабость мышечного тонуса, недостаточная сформированность формообразующих движений рук. При выполнении проб на изучение уровня осязательных возможностей дети часто выбирали зрительный способ, игнорируя тактильный. Испытуемые исправляли совершенные ими ошибки. Мелкая моторика и осязательные возможности развиты близко к возрастной норме. К испытуемым с низким уровнем развития осязания и мелкой моторики (третья группа) были отнесены 25 \% (6 человек) от общего количества детей. У них был выявлен диффузный характер движений, наличие синкинезий, невозможность удержания пальцевой позы, выраженное нарушение согласованности движений, зрительно-моторной координации, скованность движений. Характер действий детей данной группы был хаотичным, испытуемые пропускали совершенные ошибки, выбирали зрительный способ изучения предмета, что свидетельствовало об отсутствии стремления к осязательному обследованию образца. Мелкая моторика и осязательные возможности ограничены. Таким образом, преобладающий средний и низкий уровень развития осязательных возможностей и мелкой моторики указывал на необходимость интенсификации коррекционной работы по их развитию.

Дальнейшая опытно-экспериментальная работа была направлена на разработку организационно-методических основ коррекционной работы по развитию осязания и мелкой моторики у дошкольников с ОНР. В рамках нашего исследования было разработано содер- 
жание логопедических занятий, включающих комплекс специальных приемов и упражнений, направленных на развитие осязания и мелкой моторики детей дошкольного возраста с ОНР, в том числе посредством использования интерактивного дидактического пособия «Игрокуб». Охарактеризуем разработанное нами пособие.

Комплекс «Игрокуб» состоит из деревянной основы и крепящихся на нее 9 сменных панелей с заданиями. Для хранения панелей предусмотрен ящик, входящий в основу комплекса. На верхней грани «Игрокуба» расположен лабиринт - основание с закрепленными на нем изогнутыми проволоками, на которые нанизаны разноцветные бусины разной формы. Перемещение ребенком бусин по проволокам тренирует мелкую моторику и сообразительность. Панель «Веселые нити» представлена доской с вбитыми гвоздиками. Дополнительным инструментарием для работы на данной панели выступают резиночки, из которых моделируются плоскостные фигуры, элементы, буквы. Панель «Домик-гномик» оформлена в виде домика с дверцами. Для отработки действий большого и указательного пальцев дверь закрыта на шпингалет, на другой двери висит замок с ключом для отработки действий двумя руками. Панель «Проведи детеныша к маме» представлена пальчиковым лабиринтом, предназначенным для развития запястья, пальцевого захвата, развития зрительно-моторной координации. Развивающее панно «Игры на липучках» представляет собой доску с липучками и комплекты предметов для крепления, сгруппированные по темам: «Одежда», «Овощи» и т.д. Многообразие материала деталей (фетр, атлас, ситец) отражает тактильно воспринимаемые свойства предмета, позволяет развивать осязательные возможности ребенка. Панель «Часы» выполнена в виде изображений внешней и внутренней (шестеренки) стороны часов, что позволяет сформировать представления о понятиях «время», «минута», «час». Передвижение стрелки указательным пальцем способствует развитию пальцевого праксиса, а прокрутка шестеренок активизирует работу всей кисти ребенка. Для совершенствования скоординированных движений пальцев рук предусмотрена панель «Цветные узоры». На верхнем крае панели прикреплены цветные ленты, из которых пронизывающими движениями необходимо составить узор на пластмассовой основе с прорезями. Панель «Волшебные мешочки», представляющая собой доску с отверстиями, к которым прикреплены мешочки, позволяет развивать осязательные возможности ребенка. Наполнение данных мешочков может быть различным, что обеспечивает вариативность работы. Панель «Шнуровка» включает в себя 5 нитей для нанизывания бусин и наборы бусинок различной формы и тематики (цифры, транспорт и т.д). Разнообразие форм деталей совершенствует тактильные ощущения ребенка, а распределение бусин по различным критериям развивают логику, знакомят с окружающим миром, помогают освоить счет. Таким образом, разработанное нами пособие интегрирует в себе как известные и широко применяемые виды упражнений, так и оригинальные, обладая тем самым многофункциональностью и многовариантностью в работе, в отличие от существующих аналогов, которые в большинстве случаев позволяют выполнять единственный вариант упражнений. Разнообразие заданий с использованием «Игрокуба» позволяет поддерживать устойчивый интерес дошкольников к занятиям с ним. Конструкция «Игрокуба» разборная, что позволит в перспективе дополнить уже разработанные панели и другими вариантами.

С применением «Игрокуба», а также других средств, были реализованы основные направления коррекционной работы.

І. Развитие мелкой моторики рук. Коррекционная работа по данному направлению заключалась в развитии пальцевого, кистевого, ладонного захвата предметов разной величины, развитии точных движений рук. Работа осуществлялась как при использовании дополнительных предметов, так и без их применения. Для реализации данного направления использовались следующие приемы: подражание демонстрируемым изолированным движениям рук, кистей, пальцев рук (статические, динамические); захват (пальцевый, кистевой, ладонный), удержание предметов (мелких, крупных, средних) одной, двумя руками и перекладывание их из одной руки в другую; завинчивающие, надавливающие, сжимающие, собирающие, перемещающие, нанизывающие движения.

II. Развитие мелкой моторики в процессе игровой деятельности. Ведущий вид деятельности дошкольников - игра, поэтому важным направлением развития осязания и мелкой моторики является формирование умения использовать данные функции в процессе игры. Для реализации направления были разработаны игры с предметами и дидактическими материалами, дидактическая задача в которых предполагала: сортировку мелких предметов, собирание и перекладывание предметов; накладывание, прикладывание, совмещение, нанизывание мелких и крупных предметов; наматывание нити на катушку, разглаживание салфетки; выкладывание контура предмета палочками, нитями, бусинами, мелкими шариками и др.

III. Формирование осязательного обследования с использованием сенсорных эталонов. Содержание коррекционной работы по выделенному направлению включало формирование навыков выделения эталонов формы и величины предметов. При развитии данных навыков использовались объемные и плоскостные геометрические фигуры. Коррекционные задачи были реализованы в процессе осязательного обследования ребенком 
предлагаемых объектов и осуществлялись при использовании следующих приемов: ощупывание и обводящие мануальные действия округлых и угольных объемных и плоскостных геометрических фигур; выбор фигуры на ощупь (из трех-пяти) по образцу; соотнесение геометрического эталона с предметным изображением простой конфигурации, выполненном в силуэтном и контурном вариантах; классификация предметов с учетом градации величин и др.

IV. Формирование навыков выделения сенсорных эталонов осязательных признаков предмета осуществлялось при использовании приемов: название тактильных признаков предмета; выбор тождественного предмета по качеству поверхности их двух (трех) предложенных зрительно-осязательным, осязательным способом; выбор предмета по словесному предъявлению осязательного признака и др.

Одним из методов развития осязания и мелкой моторики в коррекционно-развивающем процессе нами были выбраны пальчиковые игры. В данном блоке мы использовали традиционную пальчиковую гимнастику, массаж и самомассаж кистей рук. В комплекс пальчиковых игр нами также был включен массаж при использовании дополнительных предметов (шариков, прищепок). Например, испытуемым предлагалось кратковременно поочередно надевать на пальцы рук прищепки, катать шарик между ладонями и одной ладонью попеременно.

Для подготовки руки для успешного овладения навыками письма старшими дошкольниками нами были использованы графические задания: выполнение «дорожек» разной формы, обводка по контурным линиям, точкам, трафарету, различные варианты штриховок и др.

Обязательным условием выполнения ребенком приемов и упражнений на развитие осязания и мелкой моторики являлось соблюдение следующего алгоритма, включающего два этапа:

І. этап - подготовительный, заключающийся в подготовке руки к воспроизведению движений и осязательному обследованию предмета. Данный этап включает элементы классического массажа.

II. этап - основной, включающий непосредственное выполнение упражнения для развития осязания и мелкой моторики.

Работа по развитию осязания и мелкой моторики дошкольников с ОНР, проводимая на логопедических занятиях, интегрируется в коррекционные занятий по преодолению речевых нарушений и осуществляется логопедом. В ходе обучения приемы развития осязания и мелкой моторики мы включали в различные этапы лого- педического занятия (этап автоматизации звука в слогах, словах, предложения, этап дифференциации звуков, этап соотнесения звука с буквой и т.д.). Приведем пример.

Этап автоматизации звука изолированно. Упражнение «Изолированный звук» (с использованием панели «Лабиринт»).

- Буратино к нам шел долго и слушал звуки природы. Ему очень понравились песенка водички - ссс и песенка комара - 3зз. Он стал петь то одну, то другую. Давай и мы споём песенку водички и песенку комара. Произноси долго ссс и веди бусинку синего цвета, а при песенке комара (ззз) - перемещай зеленые бусины.

Этап соотнесения звука с буквой. Упражнение «Алфавит» (при использовании панели «Веселые нити»).

- Звукам [C] и [3] соответствуют буквы C и 3. Давай вспомним, как они пишутся, и напишем их в прописи. Как ты думаешь, на что похожи эти буквы? Давай построим их на гвоздиках с помощью резиночек.

Этап развития лексико-грамматического строя речи. Упражнение «Чей голос прозвучал?» (с использованием панели «Шнуровка»).

- Каждое животное на ферме разговаривает поразному, кто-то мычит, кто-то лает. Давай послушаем голоса животных и наденем на ниточку бусину с изображением того животного, чей голос прозвучал.

Этап автоматизации звука в словах. Дидактическая игра «Волшебные бусины» (с использованием панели «Лабиринт»)

- Давай покатаем звук [P] на бусинах. Если звук [P] стоит в начале слова, то мы повезем его на красной бусине, если в середине, то на синей, а если звук [Р] стоит в конце слова - на зеленой.

Для анализа эффективности проведенного формирующего обучения нами был проведен контрольный эксперимент, который показал эффективность применения данного средства в коррекционной работе с дошкольниками с ОНР. Дети демонстрировали преимущественно высокий и средний уровень развития данных способностей, количество испытуемых с низким уровнем их развития существенно снизилось. Таким образом, результатами контрольного эксперимента доказана эффективность осуществленного формирующего обучения и целесообразность применения в коррекционноразвивающей работе по развитию осязания и мелкой моторики детей старшего дошкольного возраста с ОНР интерактивного дидактического пособия «Игрокуб». 


\section{ЛИТЕРАТУРА}

1. Бобык С.С. Развитие тактильного восприятия у детей дошкольного возраста с речевыми нарушениями // Образование и воспитание. - 2018. - № 3. C. 11-14. - URL: https://moluch.ru/th/4/archive/94/3377/ (дата обращения 20.02.2021). - Текст : электронный.

2. Земляченко М.В. Формирование мелкой моторики и развитие речи дошкольников / М.В. Земляченко, Т.В. Кутергина, Т.Д. Кузнецова. Текст - непосредственный // Проблемы и перспективы развития образования : материалы V Международной научной конференции. - Пермь: Меркурий, 2014. - С. 169-172.

3. Игровой комплект «ПЕРТРА». Набор психолога : методические рекомендации. - Москва : ИНТ, 2014. - Текст : непосредственный.

4. Иневаткина С.Е. Организация психолого-педагогического сопровождения дошкольников с общим недоразвитием речи / С.Е. Иневаткина, Е.М. Каризина. - Текст : непосредственный // Специальное образование. - 2018. - № 3(51). - С. 51-59.

5. Каффеманас Р.Ф. Сравнительное исследование осязания у аномальных детей разных категорий / Р.Ф. Каффеманас. - Текст : непосредственный // Дефектология. - 1991. - № 5. - С. 14-19.

6. Минаева Н.Г. Исследование уровня развития осязания и мелкой моторики дошкольников с общим недоразвитием речи / Н.Г. Минаева, А.В. Зинюхина // Проблемы современного педагогического образования. - 2021. - № 71-3. - С. 78-81.

7. Моурлот Л.И. Развитие ручной и пальцевой моторики у детей дошкольного возраста: учебно-методическое пособие / Л.И. Моурлот, Л.А. Ремезова. Самара : СГПУ, 2007 - 122 с. - Текст : непосредственный.

8. Филичева Т.Б. Подготовка к школе детей с общим недоразвитием речи в условиях специального детского сада : пособие для студентов дефектологических факультетов, практических работников специальных учреждений, воспитателей детских садов, родителей / Т.Б. Филичева, Г.В. Чиркина. - Москва : Альфа, 1993 - 103 c. - URL: http://pedlib.ru/Books/1/0146/1_0146-4.shtml\#book_page (дата обращения: 24.02.2018). - Текст : электронный.

( ) Минаева Наталья Геннадьевна (natmi27@yandex.ru), Зинюхина Анастасия Владимировна (znastya98@mail.ru).

$$
\text { Журнал «Современная наука: актуальные проблемы теории и практики» }
$$

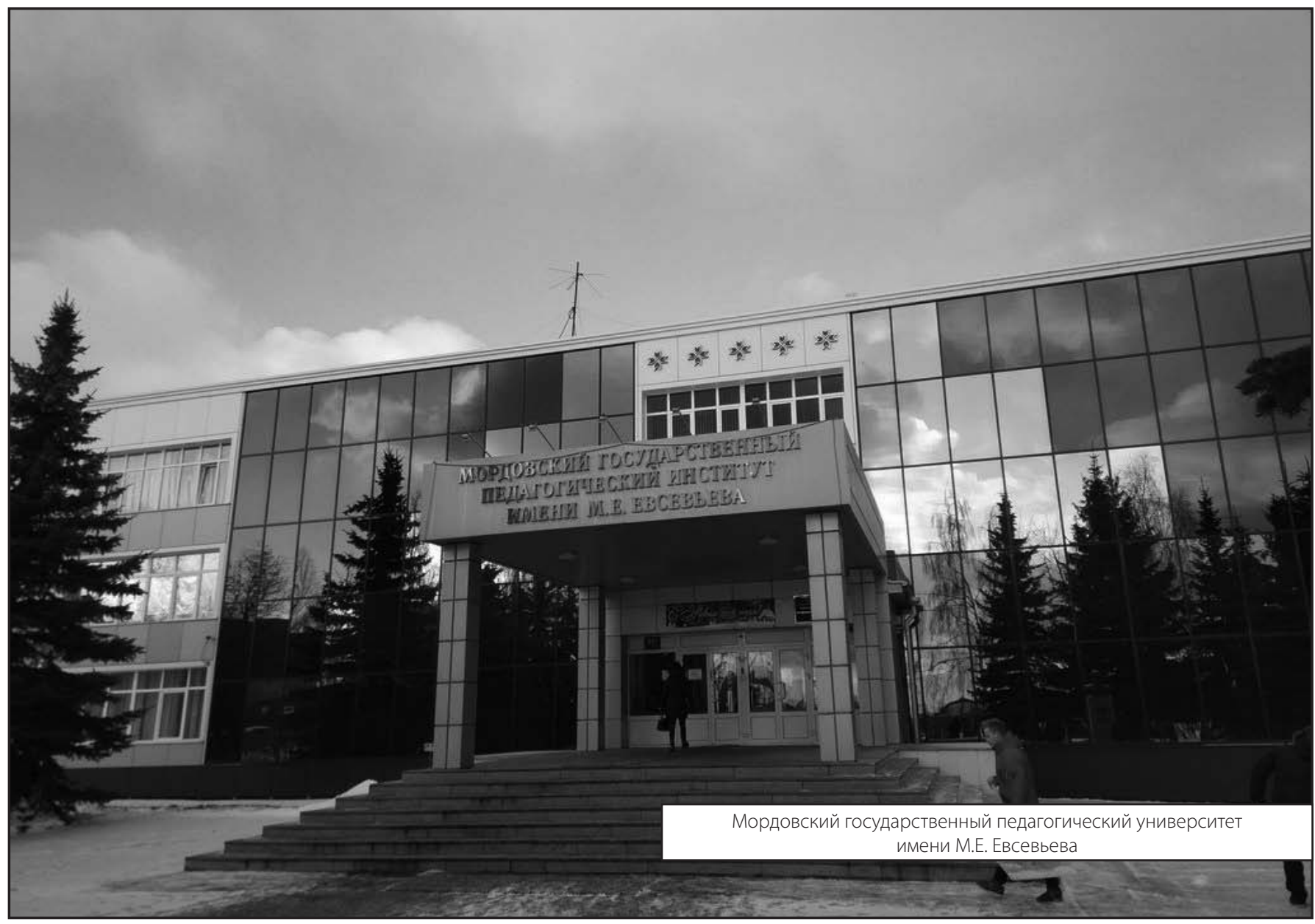

